\title{
The Evaluation of Electric Power by Separate Analysis of Fourier Transform Components
}

\author{
Ivan Kostiukov \\ National Technical University "Kharkiv Polytechnic Institute", Kharkiv, Ukraine
}

\author{
Article History \\ Received: \\ 24 November 2021 \\ Accepted: \\ 29 December 2021 \\ Published online: \\ 30 December 2021 \\ Keywords \\ Spectral Methods; \\ Spectral Leakage; \\ Bias of Estimation; \\ Phase Shift; \\ Harmonic Signal; \\ Apparent Power
}

\begin{abstract}
This paper presents a substantiation of an approach for the evaluation of components of apparent power and intended to simplify the computational procedures which usually should be implemented in order to process the preliminary sampled waveform of instantaneous power. The results of carried out studies have shown that both active and reactive power can be calculated by the analysis of calculated components of sine and cosine Fourier transforms. This paper also presents the discussion of restrictions, which should be imposed on the duration of the analyzed signal and on frequencies of the auxiliary trigonometric functions, which are applied in order to calculate components of Fourier transform which are used for the evaluation of active and reactive power. The compliance with these restrictions allows us to eliminate the undesirable bias of active and reactive power estimation caused by the refusal from the decomposition of the analyzed waveform of the instantaneous power by applying the complete system of orthogonal trigonometric functions, as the evaluation of components of the apparent power is attained based on separate analysis of sine and cosine Fourier transforms calculated for the analyzed signal. The results of carried out simulations illustrate the frequency dependencies of sine Fourier transform calculated for the case of compliance with the restrictions, which allow to attain the highest accuracy of estimation and for the case when the duration of analyzed signal does not fit these restrictions.
\end{abstract}

\section{INTRODUCTION}

The problem of accurate active and reactive power evaluation remains pretty actual for many practical issues existing in electrical engineering. Mentioned problem has a significant importance, for example, in technical applications which regard the control and monitoring of the electrical energy [1-4], the analysis of technical performance of asynchronous electric drivers with semiconductor converters [5] and also, taking into account that the deterioration of electrical insulation is accompanied by the increasing of the dependent on dissipated in dielectric material active power dissipation factor [6], for problems which are inextricably linked with the assessment of quality of the electrical insulation $[7,8]$.

The majority of studies dedicated to the increasing of accuracy of active and reactive power measurement can be divided in two main groups. The first group consists of studies which are focused on the development and analysis of various measurement tools $[9,10]$.
The studies which belong to the second group are mostly focused on the development of various techniques which can be used in order to process the preliminary sampled waveforms the electric power. These signal processing techniques usually are intended to operate either in time or in frequency domain [11]. For both cases the accuracy of estimation is affected by the undesirable spectral leakage effects, which emerge due to the finite duration of the analyzed signals and their non-coherent sampling. In frequency domain the development of such algorithms can be implemented based either on the consecutive evaluation of amplitude and the initial phase of the analyzed waveform of instantaneous power, or can be carried out by calculating corresponding to the zero bin element of the discrete Fourier transform.

The mitigation of the undesirable spectral leakage effect is attained by spectral windowing and interpolation of calculated coefficients of the Fourier transform [12-14]. Despite the proven advantages of these approaches, practical implementation of algorithms based on spectral windowing with further

Corresponding author: ivan.kostiukov@khpi.edu.ua (Ivan Kostiukov)

(C) 2021 The Author(s). Published by O. M. Beketov National University of Urban Economy in Kharkiv Use permitted under Creative Commons Attribution 4.0 International (CC BY 4.0)

Cite as: Kostiukov, I. (2021). The evaluation of electric power by separate analysis of Fourier transform components. Lighting Engineering \& Power Engineering, 60(3), 133-139. https:/ / doi.org/10.33042/2079-424X.2021.60.3.06 
interpolation of calculated coefficients of Fourier transform complicates the processing of analyzed signals. Mentioned circumstance urges the development of methods for power estimation, which would allow to simplify signal processing procedures.

This paper is focused on the development of one of such approaches, which is based on separate analysis and specific properties of sine and cosine Fourier transforms, calculated for analyzed waveform of instantaneous power with previously specifically selected duration. Since the evaluation of active and reactive power can be carried out on the basis of a single calculation of Fourier transform, such approach for power estimation enhances the computational efficiency of algorithms, as it allows to obtain the necessary information concerning the components of apparent power by applying smaller number of computational procedures.

\section{SUBSTANTIATION OF THE DEVELOPED APPROACH FOR POWER ESTIMATION}

Further analysis of properties of sine and cosine Fourier transform, which have been used as the basis for the developed approach for power estimation, will be carried out assuming that time dependence of the analyzed waveform of instantaneous active power $p(t)$ can be expressed as follows:

$$
p(t)=p_{0}+p_{V}(t)
$$

where $p_{0}$ and $p_{V}(t)$ correspondingly denote the time independent and alternating components of instantaneous power and can be expressed as:

$p_{0}=\frac{A_{2}}{2} \cos \left(\varphi_{2}\right)$

$p_{V}(t)=-\frac{A_{2}}{2} \sin \left(\omega_{2} t+\varphi_{2}\right)$

where $\varphi_{2}$ denotes the value of phase shift between the sine curves of current and voltage; $\omega_{2}$ and $A_{2}$ correspondingly denote the value of angular frequency of instantaneous power and its amplitude, which depends on the result of the multiplication of amplitudes of sine the curves of current and voltage.

The parameters of analyzed signal $A_{2}$ and $\varphi_{2}$ are considered to be unknown and unavailable for direct measurements, whereas the value of $\omega_{2}$ is assumed to be equal to the doubled value of angular frequency of power system. Relation (2) can be used for the calculation of active power, whereas the value of the reactive power can be calculated as follows:

$s_{0}=\frac{A_{2}}{2} \sin \left(\varphi_{2}\right)$.
The direct calculation of the determined according to Eq. (2) active power can be carried out based on the calculation of element of Fourier transform which corresponds to the zero bin. This approach is identical to the averaging of the analyzed sampled waveform over one period or over an integer number of periods and usually is affected by the undesirable desynchronization between the sampling frequency and the exact frequency of the analyzed signal, which either results in the existence of some contribution from the belonging to other periods samples of the analyzed signal, or leads to the certain shortage of taken into account samples and, consequently, degrades the overall accuracy of estimation.

The analysis of properties of sine and cosine Fourier transforms, which allow to carry out the evaluation of electric power based on their separate analysis, will be carried out based on analytical evaluation of the following expressions:

$$
\begin{aligned}
& B_{s}=\int_{0}^{b} \sin \left(\omega_{1} t\right) p(t) d t, \\
& B_{c}=\int_{0}^{b} \cos \left(\omega_{1} t\right) p(t) d t,
\end{aligned}
$$

where $\omega_{1}$ denotes the value of angular frequency of used in Eqs. (5), (6) auxiliary sine and cosine functions and $b$ denotes the duration of the analyzed signal. The developed approach for power estimation is premised on the analytical expressions for $B_{s}$ and $B_{c}$ which, however, should be derived for two antithetical cases: $p_{0}(t)=0, \omega_{1}=\omega_{2}$ and $\omega_{1} \neq \omega_{2}, p_{0}(t) \neq 0$. Assuming that the value of angular frequency of the auxiliary sine and cosine functions is equal to the frequency of the analyzed signal, i.e. the case of $\omega_{1}=\omega_{2}$ and $p_{0}(t)=0$, the relations for $B_{s}$ and $B_{c}$ in expanded form can be expressed as:

$$
\begin{aligned}
& B_{s e}=\sum_{i=1}^{4} B_{s e i}, \\
& B_{c e}=\sum_{i=1}^{4} B_{c e i},
\end{aligned}
$$

where $B_{s e}$ and $B_{c e}$ correspondingly denote the values of $B_{s}$ and $B_{c}$ expressed for the case of $\omega_{1}=\omega_{2}$, $p_{0}(t)=0$ and all terms $B_{s e 1} \ldots B_{s e 4}$ and $B_{c e 1} \ldots B_{c e 4}$ can be determined as:

$$
\begin{aligned}
& B_{s e 1}=\frac{A_{2}}{4} \sin \left(\varphi_{2}\right) b, \\
& B_{s e 2}=-\frac{A_{2}}{4 \omega_{1}} \cos \left(\varphi_{2}\right),
\end{aligned}
$$


$B_{s e 3}=\frac{A_{2}}{4 \omega_{1}} \cos \left(\varphi_{2}\right) \cos ^{2}\left(b \omega_{1}\right)$,

$B_{s e 4}=-\frac{A_{2}}{4 \omega_{1}} \sin \left(\varphi_{2}\right) \sin \left(b \omega_{1}\right) \cos \left(b \omega_{1}\right)$,

$B_{c e 1}=-\frac{A_{2}}{4} \cos \left(\varphi_{2}\right) b$,

$B_{c e 2}=\frac{A_{2}}{4 \omega_{1}} \sin \left(\varphi_{2}\right)$,

$B_{c e 3}=-\frac{A_{2}}{4 \omega_{1}} \sin \left(\varphi_{2}\right) \cos ^{2}\left(b \omega_{1}\right)$,

$B_{c e 4}=-\frac{A_{2}}{4 \omega_{1}} \cos \left(\varphi_{2}\right) \sin \left(b \omega_{1}\right) \cos \left(b \omega_{1}\right)$.

For the case of $\omega_{1} \neq \omega_{2}$ and $p_{0}(t) \neq 0$ the relations for $B_{s}$ and $B_{c}$ in expanded form can be expressed as

$$
\begin{aligned}
& B_{s n}=\sum_{i=1}^{7} B_{s n i}, \\
& B_{c n}=\sum_{i=1}^{4} B_{c n i},
\end{aligned}
$$

where $B_{s n}$ and $B_{c n}$ denote the values of $B_{s}$ and $B_{c}$ expressed for the case of $\omega_{1} \neq \omega_{2}, p_{0}(t) \neq 0$ and all terms $B_{s n 1} \ldots B_{s n 7}$ and $B_{c n 1} \ldots B_{c n 7}$ can be expressed as:

$$
\begin{aligned}
& B_{s n 1}=\frac{A_{2} \omega_{2} \sin \left(b \omega_{1}\right) \sin \left(b \omega_{2}\right) \cos \left(\varphi_{2}\right)}{2\left(\omega_{1}-\omega_{2}\right)\left(\omega_{1}+\omega_{2}\right)}, \\
& B_{s n 2}=\frac{A_{2} \omega_{2} \sin \left(b \omega_{1}\right) \cos \left(b \omega_{2}\right) \sin \left(\varphi_{2}\right)}{2\left(\omega_{1}-\omega_{2}\right)\left(\omega_{1}+\omega_{2}\right)}, \\
& B_{s n 3}=\frac{A_{2} \omega_{1} \cos \left(b \omega_{1}\right) \cos \left(b \omega_{2}\right) \cos \left(\varphi_{2}\right)}{2\left(\omega_{1}-\omega_{2}\right)\left(\omega_{1}+\omega_{2}\right)}, \\
& B_{s n 4}=-\frac{A_{2} \omega_{1} \cos \left(b \omega_{1}\right) \sin \left(b \omega_{2}\right) \sin \left(\varphi_{2}\right)}{2\left(\omega_{1}-\omega_{2}\right)\left(\omega_{1}+\omega_{2}\right)}, \\
& B_{s n 5}=-\frac{A_{2} \omega_{1} \cos \left(b \omega_{1}\right) \cos \left(\varphi_{2}\right)}{2\left(\omega_{1}-\omega_{2}\right)\left(\omega_{1}+\omega_{2}\right)}, \\
& B_{s n 7}=\frac{A_{2} \omega_{2}^{2} \cos \left(b \omega_{1}\right) \cos \left(\varphi_{2}\right)}{2 \omega_{1}\left(\omega_{1}-\omega_{2}\right)\left(\omega_{1}+\omega_{2}\right)}, \\
& B_{c n 1}=\frac{A_{2} \omega_{2}^{2} \cos \left(\varphi_{2}\right)}{2 \omega_{1}\left(\omega_{1}-\omega_{2}\right)\left(\omega_{1}+\omega_{2}\right)}, \\
& 2\left(\omega_{1}-\omega_{2}\right)\left(\omega_{1}+\omega_{2}\right)
\end{aligned}
$$

$B_{c n 3}=\frac{A_{2} \omega_{1} \sin \left(b \omega_{1}\right) \sin \left(b \omega_{2}\right) \sin \left(\varphi_{2}\right)}{2\left(\omega_{1}-\omega_{2}\right)\left(\omega_{1}+\omega_{2}\right)}$,

$B_{c n 4}=-\frac{A_{2} \omega_{1} \sin \left(b \omega_{1}\right) \cos \left(b \omega_{2}\right) \cos \left(\varphi_{2}\right)}{2\left(\omega_{1}-\omega_{2}\right)\left(\omega_{1}+\omega_{2}\right)}$,

$B_{c n 5}=\frac{A_{2} \omega_{1} \sin \left(b \omega_{1}\right) \cos \left(\varphi_{2}\right)}{2\left(\omega_{1}-\omega_{2}\right)\left(\omega_{1}+\omega_{2}\right)}$

$B_{s n 6}=-\frac{A_{2} \omega_{2}^{2} \sin \left(b \omega_{1}\right) \cos \left(\varphi_{2}\right)}{2\left(\omega_{1}-\omega_{2}\right)\left(\omega_{1}+\omega_{2}\right)}$,

$B_{c n 7}=-\frac{A_{2} \omega_{2} \sin \left(\varphi_{2}\right)}{2\left(\omega_{1}-\omega_{2}\right)\left(\omega_{1}+\omega_{2}\right)}$.

The applying of the derived relations for $B_{s e}$, $B_{c e}$ and $B_{s n}, B_{c n}$ for the purposes of the evaluation of active and reactive power is possible provided that the duration of analyzed signal fits the equality: $\sin \left(b \omega_{2}\right)=0$ and the frequencies of used in Eqs. (5), (6) auxiliary trigonometric functions $\sin \left(\omega_{1} t\right)$ and $\cos \left(\omega_{1} t\right)$, which provide the decomposition of the analyzed signal, are expressed as:

$f_{s 1}=\frac{k}{2 b}$

where $k=1 \ldots N$ and denotes the number of a particular frequency of used in Eqs. (5), (6) auxiliary trigonometric function, among the total number of frequencies $N$. For the case when the frequencies of the auxiliary functions $\cos \left(\omega_{1} t\right)$ in Eq. (2) have been selected according to Eq. (30) all the determined according to Eqs. (19)-(32) terms $B_{s n 1} \ldots B_{s n} 7$ which contain the dependent on the duration of analyzed signal multiplier $\sin \left(\omega_{1} t\right)$ will not contribute to the determined according to Eqs. (17), (18) overall sums $B_{s n}$ and $B_{c n}$ due to the ensured equality: $\sin \left(b \omega_{1}\right)=0$. Such selection simultaneously leads to the increasing of impact of terms $B_{s n 1} \ldots B_{s n 7}$ and $B_{c n 1} \ldots B_{c n 7}$ which contain the multiplier $\cos \left(b \omega_{1}\right)$, as for the case of the selected according to Eq. (33) frequencies of the auxiliary trigonometric functions this multiplier, depending on the particular value of $\omega_{1}$, will be equal either to 1 or to -1 . Provided that the frequencies of the auxiliary trigonometric functions in Eqs. (5), (6) have been selected according to Eq. (33) and the duration $b$ of the analyzed signal fits the equality: $\sin \left(b \omega_{2}\right)=0$, it can be shown that the values of active and reactive power can be evaluated by calculating the determined according to Eqs. (5), (6) inner products of analyzed signals. For this case the values of active and reactive power, respectively, can be derived from the element of calculated for the case of $\omega_{1}=\omega_{2}$ inner products Eqs. (5), (6), as this very element remains unaffected 
by the time independent component of the analyzed signal $p_{0}$. For the case of the based on Eq. (6) calculation of the reactive power this approach for estimation can be substantiated by considering the limit of the determined according to Eq. (17) value of $B_{s n}$ assuming that the angular frequency of the analyzed signal $\omega_{2}$ is approaching the used in Eq. (6) value of the angular frequency $\omega_{1}$ :

$$
S=\lim _{\omega_{2} \rightarrow \omega_{1}} \sum_{i=1}^{7} B_{s n i}=\sum_{i=1}^{5} S_{s n i},
$$

where all terms $S_{s n 1} \ldots S_{s n 5}$ can be expressed as:

$$
\begin{aligned}
& S_{s n 1}=B_{s e 1}, \\
& S_{s n 2}=\frac{A_{2} \cos \left(\varphi_{2}\right)}{4 \omega_{1}}, \\
& S_{s n 3}=-\frac{A_{2} \cos \left(b \omega_{1}\right) \cos \left(\varphi_{2}\right)}{2 \omega_{1}}, \\
& S_{s n 4}=\frac{A_{2} \cos ^{2}\left(b \omega_{1}\right) \cos \left(\varphi_{2}\right)}{4 \omega_{1}}, \\
& S_{s n 5}=-\frac{A_{2} \cos \left(b \omega_{1}\right) \sin \left(b \omega_{1}\right) \sin \left(\varphi_{2}\right)}{4 \omega_{1}} .
\end{aligned}
$$

The determined according to Eq. (34) equality was put into the basis of the developed approach for the evaluation of reactive power. The coincidence of terms $S_{s n 1}$ and $B_{s e 1}$, which was not disrupted by the fact that the expression for $B_{s e 1}$ was derived for the idealized case of $p_{0}=0$, whereas Eqs. (34), (35) was obtained for the more practical case of $p_{0} \neq 0$, allows us to carry out calculation of the reactive power according to:

$S=\frac{2}{b} S_{s n 1}$

The existence of the additional terms $S_{s n 2} \ldots S_{s n 5}$ in Eq. (34) and $B_{s e 2} \ldots B_{s e}$ in Eq. (7), which may contribute to the calculated according to Eqs. (7), (34) sums $B_{s e}$ and $S$ and make Eq. (40) inapplicable due the biased value of $S_{s n 1}$ because of the existence of some contribution of $S_{s n 2} \ldots S_{s n 5}$, however, does not lead to any inaccuracy of estimation. The elimination of their impact is attained by the based on Eq. (33) selection of frequencies of the auxiliary functions $\cos \left(\omega_{1} t\right)$. Previously mentioned removal of terms which contain the multiplier $\sin \left(b \omega_{1}\right)$ allows us to exclude $B_{s e 4}$ in Eq. (4) and $S_{s n 5}$ in Eq. (34), whereas the dependent on $\omega_{1}$ alternating equality either to 1 or to -1 of multiplier $\cos \left(\omega_{1} t\right)$ leads to the mutual compensation of terms $B_{s e 2}$ and
$B_{s e 3}$ in Eq. (7) and $S_{s n 2} \ldots S_{s n 4}$ in Eq. (34). Thus, under the previously imposed on the duration of analyzed signal restrictions $\left(\sin \left(b \omega_{2}\right)=0\right)$ and for the case of the selected according to Eq. (33) frequencies of the auxiliary sine functions, the values of $B_{s e}$ and $S$ will be correspondingly determined by terms $B_{s e 1}$ and $S_{s n 1}$.

Similar results, suitable for the estimation of active power, may be obtained for the case of the determined according to Eq. (18) relation for $B_{c n}$

$$
P=\lim _{\omega_{2} \rightarrow \omega_{1}} \sum_{i=1}^{7} B_{c n i}=\sum_{i=1}^{5} P_{c n i},
$$

where all terms $P_{c n 1} \ldots P_{c n 5}$ can be expressed as:

$P_{c n 1}=B_{c e 1}$,

$P_{c n 2}=\frac{A_{2} \sin \left(\varphi_{2}\right)}{4 \omega_{1}}$,

$P_{c n 3}=\frac{A_{2} \sin \left(b \omega_{1}\right) \cos \left(\varphi_{2}\right)}{2 \omega_{1}}$,

$P_{c n 4}=-\frac{A_{2} \cos ^{2}\left(b \omega_{1}\right) \sin \left(\varphi_{2}\right)}{4 \omega_{1}}$,

$P_{c n 5}=-\frac{A_{2} \sin \left(b \omega_{1}\right) \cos \left(b \omega_{1}\right) \cos \left(\varphi_{2}\right)}{4 \omega_{1}}$

For the case when the frequencies of the auxiliary functions $\cos \left(\omega_{1} t\right)$ in Eq. (2) have been selected according to Eq. (20) all the determined according to Eqs. (42)-(46) terms which contain the multiplier $\sin \left(b \omega_{1}\right)$ will not contribute to the total sum Eq. (41), whereas containing the multiplier $\cos \left(\omega_{1} t\right)$ terms and $P_{c n 2}$ will compensate each other. Thus, the value of active power can be calculated as:

$P=\frac{2}{b} P_{s n 1}$

The presented results show that for the case of the selected according to Eq. (33) frequencies of the auxiliary trigonometric functions and the duration of analyzed signal which fits the equality: $\sin \left(b \omega_{2}\right)=0$ the values of active and reactive power can be evaluated by applying the component of sine or cosine Fourier transform which was calculated for the frequency of the auxiliary trigonometric sine and cosine functions which is equal to the frequency of analyzed waveform of instantaneous power. Therefore, the values of active and reactive power can be attributed not only to zero bin of Fourier transform, but also to the bin which corresponds to the exact frequency of the analyzed signal. The presented approach does not lead to the necessity of consecutive and separate estimation of amplitude of 
analyzed waveform and phase shift between sine curves of current and voltage, however, since the duration of analyzed signal is supposed to fit the equality: $\sin \left(b \omega_{2}\right)=0$ still remains affected by spectral leakage.

Consequently, the developed approach for the power estimation is based on the calculation of inner products Eqs. (5), (6) for the case of $\omega_{1}=\omega_{2}$ and under the restriction: $\sin \left(b \omega_{2}\right)=0$ with further calculation of reactive and active power according to Eqs. (40), (47).

\section{THE RESULTS OF CARRIED OUT SIMULATIONS}

The numerical simulations which illustrate the presented approach for the evaluation of active and reactive power have been carried out for two different cases.

The first case corresponded to the selection of frequencies of the auxiliary trigonometric functions according to Eq. (33) and the duration of the analyzed signal which allows us to ensure the equality: $\sin \left(b \omega_{1}\right)=0$, i.e. to the idealized conditions, which allow us to carry out power estimation.

For the second case the frequencies of the trigonometric functions have been also selected according to Eq. (33), however, the duration of the analyzed signal $b$ was selected arbitrarily and, therefore, the equality: $\sin \left(b \omega_{2}\right)=0$ was not ensured. The equality of terms $S_{s n 1}$ and $B_{s e 1}$ which, according to the presented in previous Section results, allows us to evaluate the reactive power according to Eq. (40) was selected as a criterion for the validation of the developed approach for power estimation. The results of simulations which were carried out for analyzed signal with $A_{2}=75 \mathrm{~W}, \varphi_{2}=5.63^{\circ}$ are presented on Figs. 1-4.

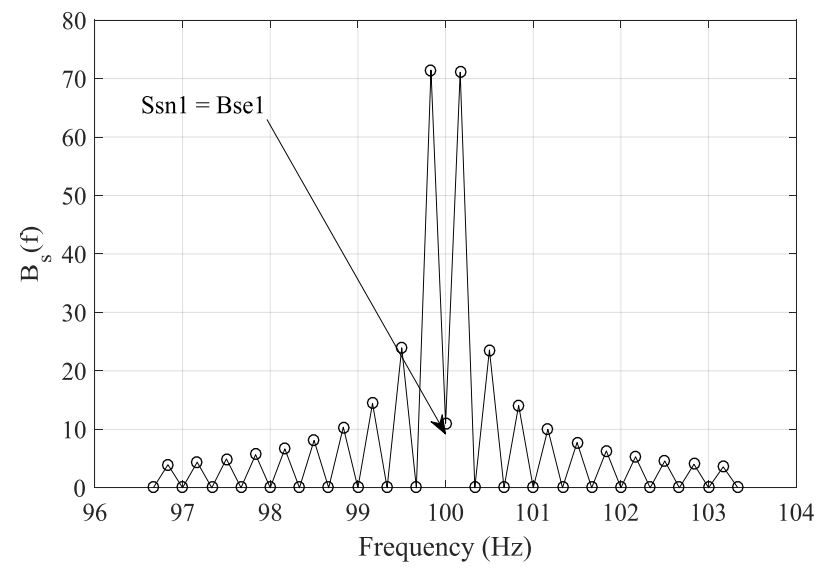

Figure 1. Frequency dependence of calculated according to Eq. (5) sine Fourier transform for the case of analyzed signal with $b=3 \mathrm{~s}$

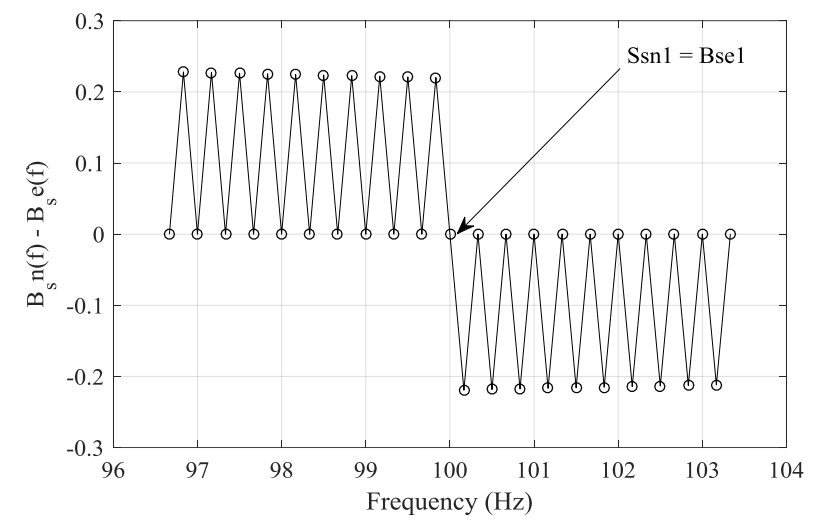

Figure 2. Difference between frequency dependencies of calculated according to Eq. (5) sine Fourier transform calculated for the cases of $p_{0}=0$ and $p_{0} \neq 0$ and analyzed signal with $b=3 \mathrm{~s}$

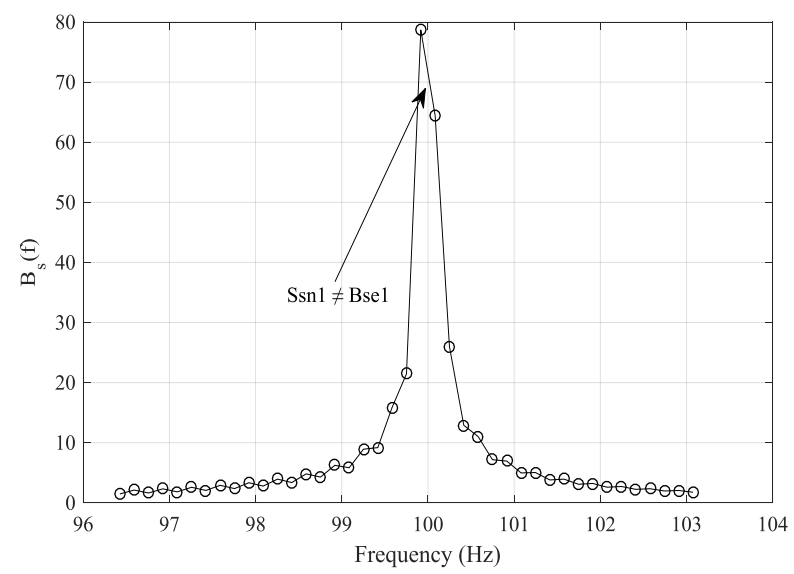

Figure 3. Frequency dependence of calculated according to Eq. (5) sine Fourier transform for the case of analyzed signal with $b=3.0075 \mathrm{~s}$

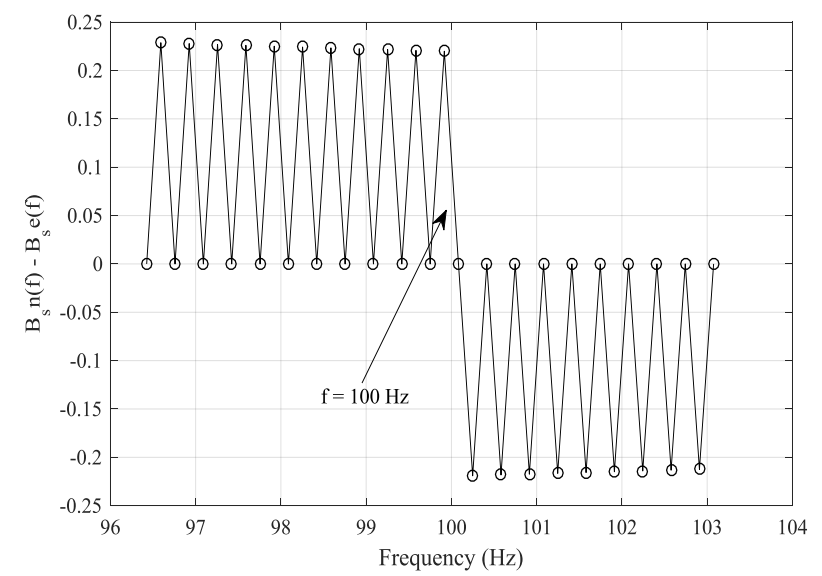

Figure 4. Difference between frequency dependencies of calculated according to Eq. (5) sine Fourier transform calculated for the cases of $p_{0}=0$ and $p_{0} \neq 0$ and analyzed signal with $b=3.0075 \mathrm{~s}$

The presented in Fig. 1 results of calculations, which were carried out for the previously described idealized case, illustrate the coincidence of terms $S_{s n 1}$ and $B_{s e 1}$ under the imposed on analyzed signal restrictions, as for the case of $f_{1}=100 \mathrm{~Hz}$ on 
Fig. 2 the resulting difference of $B_{s n}$ and $B_{s e}$ is equal to zero. The presented on Fig. 3 results illustrate the discrepancy between $S_{s n 1}$ and $B_{s e 1}$ caused by the deviation of the duration of analyzed signal. Since according to the Fig. 4 for the value of $f_{1}=100 \mathrm{~Hz}$ the resulting difference of $B_{s n}$ and $B_{s e}$ is not equal to zero, for this frequency the value of power cannot be accurately estimated based on applying of the presented approach.

\section{CONCLUSIONS}

The results of carried out studies have shown that the values of active and reactive power van be evaluated from the results of calculation of sine and cosine Fourier transforms. Accurate evaluation of these components of power is possible under the restrictions which should be imposed on the duration of analyzed signal and also on frequencies of used auxiliary trigonometric functions, which should be inversely proportional to the doubled duration of analyzed signal. Since both active and reactive power can be obtained by the analysis of the same complex sequence of calculated Fourier transform coefficients, such approach allows us to simplify the computational procedures which should be applied in order to process the analyzed signal of instantaneous power.

\section{DISCLOSURE STATEMENT}

No potential conflict of interest was reported by the author(s).

\section{REFERENCES}

1. Chica Leal, A.J., Trujillo Rodrigez, C.L., \& Santamaria, F. (2020). Comparative of power calculation methods for single-phase systems under sinusoidal and non-sinusoidal operation. Energies, 13(17), 4322. https:// doi.org/10.3390/en13174322

2. Avdakovic, S., \& Boscovic, A. (2014). Continuous wavelet and Hilbert-Huang transforms applied for analysis of active and reactive power consumption. Metrology and Measurement Systems, 21(3), 413-422. https://doi.org/ 10.2478/mms-2014-0035

3. Moghayadniya, A., \& Razavi, E. (2019). Reactive power control in micro-grid networks using adaptive control. Electrical Engineering \& Electromechancis, (5), 68-73. https://doi.org/10.20998/2074-272X.2019.5.11

4. Ayachi, B., Boukra, T., \& Mezhoud, N. (2021). Multi-objective optimal power flow considering the multi- terminal direct current. Electrical Engineering \& Electromechancis, (1), 60-66. https:// doi.org/10.20998/2074-272X. 2021.1.09

5. Kovalova, Y., Kovalov, V., \& Sherbak, I. (2021). Reactive power of asynchronous electric drivers with semiconductor converters. Lighting Engineering \& Power Engineering, 60(1), 9-14. https://doi.org/10.33042/2079-424X. 2021.60.1.02

6. Bergman, A., Bergman, S., Hoffmann, C., Paulus, E., \& Elg, A-P. (2013). Traceable measurement of dielectric dissipation factor at very low frequency. In 18th International Symposium on High Voltage Engineering (pp. 10901095). Hanyang University. https://www.diva-portal. org/smash/get/diva2:1165817/FULLTEXT01.pdf

7. Kostiukov, I. (2021). Measurement of dissipation factor of inner layers of insulation in three-core belted cables. Lighting Engineering \& Power Engineering, 60(1), 2330. https:/ / doi.org/10.33042/2079-424X.2021.60.1.04

8. Bezprozvannych, G., \& Roginsly, A. (2018). Dielectric spectroscopy of casing thermosetting composite electrical insulation system of induction traction electric machines. Electrical Engineering \& Electromechanics, (1), 17-20. https://doi.org/10.20998/2074-272X.2018.1.02

9. Toral, S.L., Quero, J.M., \& Franquelo, L.G. (2001). Reactive power and energy measurement in the frequency domain using random pulse arithmetic. IEE Proceedings Science, Measurement and Technology, 148(2), 63-67. https://doi.org/10.1049/ip-smt:20010305

10. Khlifi, K., Ayari, A., Haddouk, A., \& Mechergui, H. (2018). Measurement of active power, electrical energy, and TRMS voltage and current using the dual slope conversion technique. Turkish Journal of Electrical Engineering \& Computer Sciences, 26(2), 1081-1092. https://doi.org/ 10.3906/elk-1704-131

11. Štremfelj, J., \& Agrež, D. (2012). Apparent power estimation by interpolation of the product of the DFT coefficients. In XX IMEKO World Congress (pp. 1-6). IMECO. https://www.imeko.org/publications/wc-2012/ IMEKO-WC-2012-TC4-O21.pdf

12. Almayyali, H.R., \& Hussain, Z.M. (2021). Deep learning versus spectral techniques for frequency estimation of single tones: Reduced complexity for softwaredefined radio and IoT sensor communications. Sensors, 21(8), 2729. https://doi.org/10.3390/s21082729

13. Borkowski, J., Kania, D., \& Mroczka, J. (2018). Comparison of sine-wave frequency estimation methods in respect of speed and accuracy for a few cycles distorted by noise and harmonics. Metrology and Measurement Systems, 25(2), 283-302. https:// doi.org/10.24425/119567

14. Zhang, J.Q., \& Ovaska, S.J. (2000). An adaptive window function method for power measurement. IEEE Transactions on Instrumentation and Measurement, 49(6), 1194-1200. https:// doi.org/10.1109/19.893255

\section{Оцінювання електричної потужності шляхом окремого аналізу складових перетворення Фур'є}

Іван Костюков

Анотація. В статті представлено обгрунтування підходу до оцінки складових повної потужності, що призначений для спрощення обчислювальних процедур, які зазвичай необхідно реалізувати для обробки попередньо 
оцифрованих значень миттєвої потужності. Результати проведених досліджень показали, що як активну, так і реактивну потужність можна розрахувати шляхом окремого аналізу складових синус та косинус перетворень Фур'є. В статті також розглядаються обмеження, які необхідно накладати на тривалість досліджуваного сигналу та на частоти допоміжних тригонометричних функцій, які використовуються для розрахунку компонентів перетворення Фур'є, що потім застосовуються для оцінки активної та реактивної потужності. Дотримання цих обмежень дозволяє усунути небажану систематичну похибку розрахунку активної та реактивної потужності, що викликана відмовою від розкладання досліджуваного сигналу миттєвої потужності шляхом застосування повної системи ортогональних тригонометричних функцій, оскільки оцінка компонентів повної потужності проводиться на основі окремого аналізу синус та косинус перетворень Фур'є, розрахованих для досліджуваного сигналу. Результати проведеного моделювання ілюструють розраховані частотні залежності синус перетворення Фур'є для випадку повного дотримання наведених в статті та накладених на тривалість досліджуваного сигналу а також на частоти використаних допоміжних тригонометричних функцій обмежень, що дозволяють досягти найвищої точності оцінки потужності, а також для випадку, коли тривалість досліджуваного сигналу не відповідає цим обмеженням.

Ключові слова: спектральні методи; розтікання спектру; систематична похибка; фазовий зсув; гармонічний сигнал, повна потужність.

\section{NOTES ON CONTRIBUTORS}

\section{Ivan Kostiukov}

ivan.kostiukov@khpi.edu.ua
Ph.D., Associate Professor

Department of Theoretical Electrical Engineering

National Technical University “Kharkiv Polytechnic Institute”, Kharkiv, Ukraine

(iD) https://orcid.org/0000-0002-8923-0579

p https://publons.com/researcher/ABG-6080-2020/

SC https:// scopus.com/authid/ detail.uri?authorId=57220864135 